BULLETIN Bulletin hispanique

HISPANIQUE Université Michel de Montaigne Bordeaux

119-1 | 2017

Autorité et pouvoir dans le théâtre du Siècle d'Or

\title{
Conflictos entre autoridades literarias
}

Menéndez Pelayo, Emilio Cotarelo, Blanca de los Ríos y el teatro de Tirso de Molina

\section{Francisco Florit Durán}

\section{(2) OpenEdition}

12 Journals

Edición electrónica

URL: http://journals.openedition.org/bulletinhispanique/4826

DOI: $10.4000 /$ bulletinhispanique.4826

ISBN: 979-10-300-0142-6

ISSN: $1775-3821$

Editor

Presses universitaires de Bordeaux

Edición impresa

Fecha de publicación: 15 junio 2017

Paginación: 159-172

ISBN: 979-10-300-0141-9

ISSN: 0007-4640

\section{Referencia electrónica}

Francisco Florit Durán, «Conflictos entre autoridades literarias », Bulletin hispanique [En línea], 119-1 2017, Publicado el 15 junio 2020, consultado el 11 septiembre 2020. URL : http://

journals.openedition.org/bulletinhispanique/4826 ; DOI : https://doi.org/10.4000/bulletinhispanique. 4826

Tous droits réservés 


\title{
Conflictos entre autoridades literarias: Menéndez Pelayo, Emilio Cotarelo, Blanca de los Ríos y el teatro de Tirso de Molina
}

\author{
Francisco Florit Durán \\ Universidad de Murcia
}

Au nombre des spécialistes de l'œuvre et de la vie de Tirso de Molina à la fin du $\mathrm{XIX}^{\mathrm{e}}$ siècle et au début du $\mathrm{XX}^{\mathrm{e}}$ siècle, deux se distinguent de façon singulière: Emilio Cotarelo y Mori et Blanca de los Ríos. Outre leurs recherches sur le mercédaire et la controverse acerbe qui les a opposés, il convient de souligner un point de biographie: la relation scientifique, personnelle et épistolaire que tous deux ont entretenue, pendant des années, avec Marcelino Menéndez Pelayo.

Mots-clés: Tirso de Molina, controverse littéraire, Menéndez Pelayo, Blanca de los Ríos, Emilio Cotarelo.

Entre la nómina de estudiosos de la obra de Tirso de Molina que cabe encontrar a finales del siglo XIX y en las primeras décadas del XX sobresalen las figuras de Emilio Cotarelo y Mori y de Blanca de los Ríos. Además de sus trabajos sobre el mercedario y de la agria polémica que mantuvieron a este propósito, hay una circunstancia biográfica que se debe resaltar: la relación científica, personal y epistolar que mantuvieron durante varios ańos con Marcelino Menéndez Pelayo.

Palabras claves: Tirso de Molina, polémica literaria, Menéndez Pelayo, Blanca de los Ríos, Emilio Cotarelo.

Especially prominent amongst scholars studying the work of Tirso de Molina at the end of the $19^{\text {th }}$ century and early decades of the $20^{\text {th }}$, are the names of Emilio Cotarelo y Mori and Blanca de los Ríos. Aside from their separate work on "El Mercedario" and the bitter controversy by which it was marked, they were nonetheless united by the academic, personal and epistolary relationship which, for years, they maintained with Marcelino Menéndez Pelayo.

Keywords: Tirso de Molina, literary controversy, Menéndez Pelayo, Blanca de los Ríos, Emilio Cotarelo. 
S i tuviésemos que destacar dos autoridades literarias relacionadas con la vida $\mathcal{Y}$ y obra de Tirso de Molina, y que hubiesen llevado a cabo su tarea entre finales del siglo XIX y las primeras décadas del XX, creo que el acuerdo sería unámime a la hora de señalar tanto a Emilio Cotarelo como a Blanca de los Ríos. Con todo, lo más intersante está en el hecho de que, además de sus trabajos sobre el mercedario y de la dura polémica que sostuvieron a este propósito, hay una circunstancia biográfica que se debe resaltar: la relación científica, personal y epistolar que mantuvieron durante varios ańos con Marcelino Menéndez Pelayo $^{1}$. Esa relación en modo alguno tuvo una andadura tranquila, sino que, por lo que se refiere a Cotarelo y a Menéndez Pelayo, y a Blanca de los Ríos y a Emilio Cotarelo, tal historia tuvo episodios de franca enemistad, de palabras duras e incluso de enfrentamientos físicos. De manera que lo que se va a contar aquí va más allá de una polémica entre críticos, que indudablemente lo fue como más adelante se verá, sino que estuvo trufada de presuntas traiciones, de banderías o filiaciones de los discípulos, de ambiciones, de vanidades y, muy especialmente, de todo lo atańedero al fracasado intento de Menéndez Pelayo por dirigir la Real Academia Espańola, hecho este que le produjo -en palabras de Rodríguez Marín- "la mayor amargura de su vida» y

1. Desde muy pronto, en 1894, Menéndez Pelayo deja constancia, al redactar la reseńa del libro de Cotarelo, de su relación intelectual tanto con Blanca de los Ríos como con el propio Emilio Cotarelo. Dice así don Marcelino: La otra memoria, por el contrario, que fue la favorecida por la Academia con accésit, segundo premio o mención honorífica (no otorgándose quizá superior recompensa porque la premura del plazo del certamen, que realmente era muy corto para materia tan nueva y difícil, no permitió a su discreta autora, dońa Blanca de los Ríos, presentar terminados algunos capítulos ni dar a su trabajo la postrera lima) es un estudio de investigación propia y de grandísima novedad e importancia, que contiene muchos y positivos descubrimientos, los cuales muy en breve han de ser del dominio público, para honra y prez del nombre de la erudita y modesta escritora sevillana, en quien dignamente revive el espíritu de sagaz indagación crítica que tanto enalteció a su inolvidable tío [Amador de los Ríos], el autor de la Historia Crítica de la Literatura Española. Tendremos, pues, quizá en este mismo año una verdadera biografía de Tirso, y entretanto, como para estímulo de la curiosidad y acicate del gusto, otro joven investigador [Emilio Cotarelo], en quien la modestia corre parejas con el sólido saber, el buen gusto y el recto juicio, ha reunido en un volumen de poco bulto y mucha sustancia sus propias investigaciones bio-bibliográficas sobre Tirso, producto de una exploración metódica en la literatura del siglo XVII, comenzando por las propias obras del poeta, no bastante consultadas hasta ahora con este fin. Tomo la cita de Marcelino Menéndez Pelayo, Estudios y discursos de crítica histórica y literaria. III, Madrid, CSIC 1941, p. 55. Acerca de los trabajos del polígrafo santanderino sobre la obra de Tirso de Molina tiene un útil artículo Ángel Valbuena Prat, «Menéndez Pelayo y Tirso de Molina», Anales de la Universidad de Murcia. Filosofía y Letras, no 15, 1956-1957, p. 521-534. Veáse también Francisco Florit Durán, «En torno a una reseña y un prólogo: Menéndez Pelayo y Tirso de Molina», Boletín de la Biblioteca de Menéndez Pelayo, no 88,2012 , p. 185-200.

2. A este respecto señala Alonso Zamora Vicente en su libro Historia de la Real Academia Española, Madrid, Espasa, 1999, p. 306 nota 55, lo que sigue: «La mayor amargura de su vida [la de Menéndez Pelayo] arranca de la elección de don Alejandro Pidal para la dirección de la Academia, en 1906 y 1907. Don Marcelino se la merecía, todos lo reconocíamos. Nadie como él para regir la institución máxima de nuestra conciencia literaria y nacional; pero el Sr. Pidal, a quien respeté siempre en vida y sigo reverenciando en su tumba, gozaba de relaciones políticas. 
consecuente quiebra definitiva de las relaciones entre el santanderino y el estudioso y editor de Tirso -que debía no poco a don Marcelino- y que Blanca de los Ríos, devotísima discípula de este hasta la náusea, aprovechó a su sabor para despacharse a gusto, como se verá en las cartas que le mandó a su maestro, contra Cotarelo.

La trayectoria de este crítico $^{3}$, nacido en Oviedo en 1857, doctor en Derecho por su universidad en 1877 y abogado ejerciente durante unos pocos años hasta que se establece en Madrid en 1880, fue la propia de un autodidacta en lo que tiene que ver con la disciplina de la investigación literaria ${ }^{4}$.

Por lo que respecta a Blanca de los Ríos, debe destacarse el hecho de que no estamos ante una mujer que tuviera estudios universitarios ni una formación reglada académicamente en materia de historia y crítica literaria. Su figura, tal y como han señalado Sánchez Dueñas y Gónzalez López 5 , se corresponde más bien a la de una persona que con una voluntad y disciplina admirables se entregó apasionadamente a la tarea de escribir en los periódicos, de impartir conferencias, de estudiar y editar la obra de los clásicos auriseculares, y, en fin, dejar escritas varias novelas, poemas y piezas dramáticas.

Emilia Pardo Bazán, dijo en 1910 de nuestra escritora lo que sigue:

Blanca de los Ríos tiene en la masa de la sangre esa devoción a las musas. Procede de una familia en que cuentan artistas y eruditos tan insignes como Amador de los Ríos, el historiador de las letras espańolas. Criada entre bienestar y cariño, rodeada de estimación y respeto, no ha luchado sino con la natural inveterada indiferencia del público y algo con el recelo y malevolencia que suscitan las escritoras. No hay nada más

En fin, que mi entrañable amigo no supo tragar la píldora, aunque luego se la doraran eligiéndole director de la Academia de la Historia».

3. Puede leerse una muy buena semblanza de la vida y obra de este erudito en la introducción que escribe Abraham Madroñal para el facsímil del estudio de don Emilio Don Francisco de Rojas Zorrilla, noticias biográficas y bibliográficas, Toledo, Real Academia de Bellas Artes y Ciencias Históricas de Toledo, 2007. Para el examen de la actividad crítica del erudito ovetense también resulta muy útil el artículo de Joaquín Álvarez Barrientos, «Emilio Cotarelo y Mori en la historiografía teatral decimonónica: recepción, regeneracionismo y aparición de "arte escénico"”, en R. Gutiérrez Sebastián y B. Rodríguez Gutiérrez, Desde la platea. Estudios sobre teatro decimonónico, Santander, Universidad de Cantabria, 2010, p. 305-27. Para una bibliografía de los estudios realizados por Cotarelo véase Valentín Azcune, «Biobliografía de don Emilio Cotarelo", Cuadernos para la Investigación de la Literatura Española, no 2 26, 2001, p. 279-300.

4. Así lo pone de relieve Menéndez Pidal en la necrológica de Cotarelo, al decir que este «como autodidacto, sin haber estudiado la carrera de Filosofía y Letras, tuvo que adquirir por sí solo la erudición básica».Ver Ramón Menéndez Pidal, «Don Emilio Cotarelo», Boletín de la Academia Española, no 23, 1936, p. 5-12.

5. Blas Sánchez Dueñas, «Blanca de los Ríos, crítica literaria», en M. J. Porro Herrera, Actas del Congreso Internacional sobre Otros 98. Literatura y Cine, Córdoba, Caja de Ahorros y Monte de Piedad de Córdoba, 2001, p. 181-192; Blas Sánchez Dueñas, "Anotaciones en torno a la obra de Blanca de los Ríos», en M. Arriaga Flórez et al., Escritoras y pensadoras europeas, Sevilla, Juanta de Andalucía, 20017, p. 625-638; y María Antonieta González López, Aproximación a la obraliteraria y periodística de Blanca de los Ríos, Madrid, Fundación Universitaria Española, 2001. 
diferente de la bohemia de una Jorge Sand que el tipo de esta literata, seńora y adamada hasta la punta de las uñas, seria y «honorable» como dicen los ingleses, en grado sumo, persona del mejor tono y de excelente educación ${ }^{6}$.

Presentadas, muy a vuela pluma, las semblanzas de dos de los protagonistas de esta historia, el tercero -Menéndez Pelayo no necesita ser presentado-, ha llegado el momento de entrar en el terreno de la polémica que mantuvieron Emilio Cotarelo y Blanca de los Ríos con el propio Menéndez Pelayo al fondo.

Para tal fin resulta necesario dar cuenta de la trastienda de esa polémica, y la trastienda no es otra que el frustrado intento de don Marcelino por conseguir la dirección de la Real Academia Española. Al quedar vacante la dirección de la docta casa, se produjo un clamor nacional a favor de que el puesto lo ocupara el erudito cántabro ${ }^{7}$, si bien la candidatura de don Marcelino fue presentada formalmente por los académicos Benito Pérez Galdós ${ }^{8}$ y Jacinto Octavio Picón. El 22 de noviembre de 1906, día de la elección del director interino, llegó a la Academia un telegrama de Santander con más de un centenar de firmas, reclamando el nombramiento de Menéndez Pelayo y protestando de antemano por cualquier otra solución. Ese mismo día se publicó en El Imparcial y en El Pais una carta firmada por ciento cuarenta y tres nombres, muchos de los cuales, en palabras de Rodríguez Gutiérrez, "iban a ser protagonistas de la vida literaria y cultural de la España que acababa de iniciar el siglo XX»?

Votaron veintiún académicos: Alejandro Pidal y Mon obtuvo dieciséis votos; Menéndez Pelayo, tres (los de Picón, José Ortega y Munilla y Juan Cavestany) ${ }^{10}$; Eduardo Saavedra, uno; Emilio Alcalá Galiano, Conde de Casa-Valencia, uno. Como bien señala Rodríguez Gutiérrez, «en la lista de votantes [de los que votaron a Alejandro Pidal] hay nombres que fueron una amarga decepción para Menéndez Pelayo: Antonio Maura, Emilio Ferrari, Emilio Cotarelo, Ramón Menéndez Pidal»" ${ }^{11}$.

El 5 de diciembre de 1907, fecha estatutaria para elección de cargos (primer jueves de diciembre), se produce la votación de un director que ya no será interino, sino que ocupará el cargo conforme al tiempo marcado por los

6. El texto de la Pardo Bazán se recoge en el Catálogo de las obras de Blanca de los Ríos de Lampérez y algunos juicios de la crítica acerca de ella, Madrid, V. H. Sanz Calleja, 1927, p. 40.

7. Entre los que apoyaron públicamente la candidatura de Menéndez Pelayo se contaban los hermanos Álvarez Quintero, Gregorio Martínez Sierra, Carlos Arniches, Joaquín Dicenta, Pío Baroja, Azorín, Antonio Machado, Felipe Trigo, Manuel Azańa, Mariano de Cavia, Augusto Barcia, Ramón Pérez de Ayala, Eduardo Zamacois, Francisco Villaespesa, Adolfo Bonilla y Sanmartín, Julio Camba, Rafael Casinos Assens y Gabriel Miró.

8. Pérez Galdós leyó su discurso de ingreso el 7 de febrero de 1897, discurso que fue contestado por Menéndez Pelayo. Véase Pedro Álvarez de Miranda, En doscientas sesenta y tres ocasiones como esta, Madrid, Real Academia Española, 2011, p. 76.

9. Borja Rodríguez Gutiérrez, "Una súbita rebelión epistolar en la república de las letras», Monteagudo, no 17, 2012, p. 97-108. La cita en la p. 98.

10. Ni Pérez Galdós ni Menéndez Pelayo pudieron, por diversas razones, asistir a la votación.

11. Borja Rodríguez Gutiérrez, «Menéndez Pelayo en la Real Academia de San Fernando. Aviso de un naufragio", Liburna, no 5, 2012, p. 122-144. La cita en la p. 125. 
estatutos de la RAE. Alejandro Pidal ${ }^{12}$ obtuvo quince votos; Menéndez Pelayo, siete $^{13}$, y el Conde de Casa-Valencia, uno. Rodríguez Gutiérrrez señala, a este propósito, lo siguiente:

La amargura de Menéndez Pelayo fue indecible. Rompió relaciones con Alejandro Pidal, con quien hasta el momento había cruzado cartas muy corteses y del que había celebrado con júbilo su llegada al gobierno. Finalizó su amistad con Emilio Cotarelo, antes discípulo y colaborador, y con el que un día se lió a bastonazos en plena calle de Alcalá. Y abandona la Academia. La edición de las obras de Lope de Vega, un encargo académico, queda interrumpida en el volumen XIII. No volvería a ello nunca. Los tomos XIV y XV se publican después de su muerte, pero ya sin los prólogos que Menéndez Pelayo nunca compuso ${ }^{14}$.

Cinco meses antes de su muerte don Marcelino no había conseguido olvidar la que para él había sido la peor de las afrentas. Nótese lo que dice en una carta, dirigida a Ramón D. Perés, y fechada el 12 diciembre de 1911:

Mi alejamiento de aquella Corporación [la Real Academia Española] es absoluto y probablemente definitivo, por razones de dignidad personal cuyo origen $\mathrm{Vd}$. conoce y que luego se han exacerbado con nuevos agravios. La Academia, sometida al ignorante capricho de los hombres políticos o a las malas artes de cualquier intrigante, va perdiendo a toda prisa su carácter literario. Conservo allí algunos buenos amigos, pero están en minoría insignificante, y para la mayor parte de los académicos no puede haber peor recomendación que la mía. He dejado de concurrir aun a las sesiones ordinarias ${ }^{15}$.

En todo este triste episodio Blanca de los Ríos deja su testimonio de inquebrantable fidelidad al maestro:

Acabo de leer el resultado de la nueva y definitiva elección de Presidente de la Academia Española. Hay horas en que la más alta elocuencia es el silencio. Pero como es noble y es bello sentirse espíritu valiente entre muchos espíritus cobardes, yo me congratulo y me honro de votar hoy con los menos, lamentando de todo corazón que mi sufragio sea tan insignificante y tan inútil. Tal como es, siento la necesidad de enviárselo, porque por ninguna recompensa humana renunciaría a la gloria de adherirse a esta derrota, su más entusiasta admiradora y respetuosa amiga ${ }^{16}$.

Está, pues, clarísima la actitud de la tirsista. Pero, ¿cuál fue la de Emilio Cotarelo? No se olvide que su condición era bien distinta a la de la escritora sevillana. Cotarelo había sido propuesto para ocupar un sillón en la Academia por Alejandro Pidal, Menéndez Pelayo y Francisco Commelerán en la junta del 27 de octubre de 1898. El 1 de diciembre es elegido por unanimidad y toma posesión el 27 de mayo de 1900. Lo interesante es que unos meses antes de ser presentado le escribe más de una carta a Menéndez Pelayo en la que le

12. Alejandro Pidal y Mon (1846-1913) fue director de la RAE desde 1906 hasta su muerte. 13. La nómina de votantes fue la siguiente: Francisco Rodríguez Marín, Pérez Galdós, Echegaray, Picón, Ortega y Munilla, Miguel Mir y el propio Menéndez Pelayo.

14. Op. cit., p. 125-126.

15. Marcelino Menéndez Pelayo, Epistolario, Madrid, Fundación Universitaria Española, 1982-1991, volumen 21, carta 855.

16. Ibid., volumen 19, carta 396. 
pide que utilice su influencia personal para que todo salga con bien ${ }^{17}$. Es más, cuando ya es elegido, le solicita a don Marcelino que «si se le ocurriese algún tema a propósito para mi discurso no deje de comunicármelo» ${ }^{18}$. No sabemos si su corresponsal le propuso algún tema, el caso es que el discurso de Cotarelo trató acerca de las imitaciones castellanas del Quijote y que fue, y esto es muy significativo, contestado por Alejandro Pidal.

Lo importante es que, por fortuna, se conserva una larga carta en la que Cotarelo le da cuenta pormenorizada a don Marcelino de por qué va a votar a Alejandro Pidal y no a él. La epístola, fechada el 16 de noviembre de 1906 -es decir, seis días antes de la elección- no tiene desperdicio y nos viene muy bien para ir marcando los hitos fundamentales de nuestra historia. Dice así:

Mi querido Maestro: Por tres conductos, aunque no directos ni enteramente autorizados, he tenido noticia de que está V. enojadísimo conmigo por no haberle ofrecido mi voto para Director de la Academia. Como mi primer impulso fue ir personalmente a enterarme, alguno hubo de manifestarme que no debía intentarlo, pues V. no me recibiría. Ante el peligro de recibir tal agravio que pondría las cosas en peor estado, me resuelvo a escribirle para disculparme, si es que puede haber culpa en mi conducta. Jamás me pasó por las mientes que, en esta ocasión, aspirase V. a presidir la Academia; claro es que no porque le creyese falto de títulos, sino porque la costumbre, casi no interrumpida en dos siglos, había sido conferir el cargo de Director a persona de alta jerarquía social, cuando la hubiese ${ }^{19}$. Y pude convencerme de esto cuando, a poco de fallecer D. Juan Valera, vi que en la casi totalidad de los habituales concurrentes a la Academia, daban como indiscutible la candidatura de D. Alejandro Pidal, persona que, aparte de aquellas circunstancias, reúne los méritos de poseer un grande entendimiento, haber publicado numerosos trabajos y prestado muchos servicios a la Academia, llevando siempre su voz en las ocasiones más solemnes. Así, pues, no dudé, a poco del fallecimiento del Conde de Cheste, en manifestar públicamente mi adhesión a la candidatura del Sr. Pidal, creyendo era también la de V. y cuando veía a toda la Academia (salvo dos personas de menor cuantía) inclinada a lo mismo. En mí se daba además la circunstancia de que no podía votar en contra de quien me ha apadrinado en la Academia, contestando a mi discurso de ingreso. Es cierto que hace unos cuatro o cinco días leí en un periódico que en frente de la candidatura de Pidal presentaban Galdós y Picón la de V. Pero como la forma en que estaba redactado el suelto y sus ignorancias respecto del día de la elección y la manera de hacerse acusaban la mano de persona ajena a la Academia, creía sería un timo periodístico para mortificar a Pidal y que V. desautorizaría tales asertos. [...] Tal es la razón de mi conducta, que V. desapasionadamente, creo juzgará muy natural y correcta. Si así no fuese sentiría haberme equivocado; pero nunca pasaré por la nota de haber faltado a una leal amistad de cerca de veinte años. Día vendrá en que V. apreciará cuales son sus verdaderos amigos: si los que siempre, en presencia y en ausencia, de palabra y por escrito procuran su honra o los que, por móviles que no quiero exponer, le colocan o

17. Por ejemplo, en la carta 623 del volumen 14 .

18. Ibid., volumen 15 , carta 68.

19. La verdad es que Alejandro Pidal cumplía perfectamente la condición de ser persona de alta jerarquía social. Era hijo de Pedro José Pidal y Carniado, marqués de Pidal y también miembro de la RAE entre 1847 y 1865 . Alejandro Pidal y Mon fue uno de los grandes nombres del partido conservador. Diputado en Cortes, ocupó el cargo de ministro de Fomento, fue embajador ante el Vaticano, y presidente del Congreso de los diputados. Ciertamente, Emilio Cotarelo se había buscado un buen padrino. 
no vacilan en colocarle en situación poco airosa por no decir completamente desairada. Como V. comprenderá deseo que, para no cometer alguna torpeza, me diga si soy o no soy su amigo. Si V. me llama iré como siempre a ponerme a su disposición; si V. no me contesta creeré que nada tengo que esperar sobre ese punto. La pérdida de su amistad lleva consigo un cambio en mi situación respecto de la Nueva Biblioteca de autores españoles. Decorosamente no puedo continuar asociado a esta empresa faltándome la confianza del Director de ella. Si no recibo orden de V. en contrario, dentro de unos días entregaré al Sr. Bailly así los manuscritos de Tirso que tengo en mi poder, como los de entremeses, para que otro se encargue de hacer los tomos correspondientes. Y crea V. que sea cualquiera su resolución nunca me negaré a confesar la grande y la suprema admiración que profeso a sus talentos y sabiduría y reconocerme el más humilde entre los que aspiran a ser sus discípulos, como lo es y b.s. $\mathrm{m}^{20}$.

Hasta donde sabemos Menéndez Pelayo no respondió por carta a Cotarelo. Tampoco conocemos si lo hizo en persona. En cualquier caso, todo hace pensar que este suceso de la RAE produjo una honda fractura en las relaciones científicas y personales entre ambos eruditos, pues se conservan testimonios que nos cuentan que don Marcelino y Cotarelo llegaron a las manos un año después. Del incidente se guarda el acta de conciliación. Es esta:

Los abajo firmantes, representantes de D. Marcelino Menéndez Pelayo y el segundo de D. Emilio Cotarelo, reunidos, para dilucidar y medir el alcance de un desagradable incidente que surgió noches pasadas entre estos dos señores, han encontrado después de confrontadas las versiones respectivas del suceso, que, como era de esperar, tratándose de personas notoriamente tan cultas, no ha habido por parte de uno ni de otro, el menor intento preconcebido de agresión ni de disputa, sino que por creer el Sr. Cotarelo que el Sr. Menéndez Pelayo había vertido un concepto inexacto, que juzgaba molesto, y por estimar este señor que la forma en que se le pedía sobre esto una explicación, implicaba una imposición que le impedía darla, hizo que se exaltaran los ánimos de los dos interlocutores, más allá de lo que estaba en el ánimo de cada uno de ellos; pero sin alcanzar más proporciones los hechos que las de un pasajero, y como queda dicho, desagradable incidente, que en nada afecta la reputación ni el honor de nuestros representados. Madrid, 12 de noviembre de 1908.

Mariano Catalina y Marqués de Pidal [Alejandro Pidal y Mon] ${ }^{21}$.

El propio Menéndez Pelayo, en una carta de 5 de marzo de 1910, le cuenta a Juan L. Estelrich con cierta amargura lo que sigue:

De la otra Academia [la RAE] nada te digo, porque hay cosas que no son para puestas por escrito. Cotarelo llegó a insolentarse conmigo en tales términos que tuve que administrarle dos garrotazos físicos o materiales en plena calle de Alcalá, hace más de un año. Miserias son todas estas que cada día me hacen más insoportable la estancia en Madrid, donde además se pierde el tiempo de una manera lastimosa ${ }^{22}$.

20. Op. cit., volumen 18, carta 983 .

21. Ibid., volumen 19 , carta 878 .

22. Ibid., volumen 20, carta 748. En una carta de 29 de mayo de 1910 don Marcelino le da cuenta a su hermano de su elección por unanimidad como senador en representación de la RAE, y añade «Parece que Pidal [Alejandro Pidal, el director de la docta casa] tuvo empeño en que no hubiese ningún voto en contra, y obligó a Cotarelo y no sé si algún otro a quedarse en casa» (Ibid., vololumen 21, carta 30). Está clara, pues, que la enemistad entre Menéndez Pelayo 
Debemos prestarle ahora atención a las cartas dirigidas por Blanca de los Ríos a su maestro. Las dos cartas que nos interesan están separadas por un mes. La primera es del 26 de julio de 1907 y la segunda del 26 de agosto. Su importancia viene dada por el contenido -bien sabroso, por cierto- de las mismas, por tener relación con el descubrimiento de un texto incompleto e inédito de Tirso y por estar escritas en plena guerra académica entre los dos estudiosos del mercedario. Una guerra, no se olvide, que tiene como objetivo principal conquistar la plaza de autoridad literaria en todo lo que tenga que ver con la vida y obra de Tirso de Molina.

Aunque son largas, creemos conveniente dar cuenta de ellas aquí y hacer algún comentario clarificador acerca de su contenido. He aquí la primera, fechada el 26 de julio de 1907:

Insigne y admirado maestro: Era mi propósito haber venido de Barcelona a tiempo de encontrar a Vd. en Madrid, pues deseaba mucho verle y que hubiésemos hablado de cosas que a Vd. y a mí nos duelen y de otras que a mí muy en particular me interesan. Motivos ajenos a mi voluntad retrasaron mi viaje, y ahora escribo a Vd. para pedirle un favor, que de veras estimaría. Es el caso que en Barcelona donde, como Vd. sabrá, me honró el Ateneo con una velada en que hablé de las relaciones entre Tirso y Cataluña, tratando de este asunto con varios literatos de allí, pude ver confirmada la creencia que hace tiempo me sugirió la lectura de cierta página de Tirso, de que éste escribió una Vida de Santa María del Socós: tan segura estaba yo de ello que a mis primeras palabras con el P. Gazulla, mercenario que estudia la historia de la Orden, le expresé mi convicción sobre este punto y el P. no supo ocultarme que, en efecto, mi presunción no iba descaminada. Pronto supe el hallazgo del presentido opúsculo. Varias personas, en Barcelona y en Madrid, me lo han descrito tan al pormenor, que sin haberlo visto, podría hacer su nota bibliográfica. Sé que se trata de un manuscrito en $8 .^{\circ}$, inédito, y autógrafo, escrito a dos columnas, e incompleto por desdicha, que contiene ciertas estrofas de Tirso, y una dedicatoria suya, autógrafa, a los Concelleres de Barcelona; conozco la fecha de la dedicatoria y otros varios pormenores que me interesan. Provista de estos datos, hablé a mi amigo Bofarull, jefe del Archivo de la Corona de Aragón, el cual no quiso decirme ni aun el nombre del descubridor del mss., aunque yo sabía que era el Sr. Palomares, Archivero de Hacienda. Inútilmente dije al Sr. Bofarull que no trataba yo de hacer con nadie lo que otros hicieron conmigo y que solo deseaba ver el documento. Todo fue inútil y confieso a $\mathrm{Vd}$. que tal tenacidad en la ocultación me disgustó de veras, y más considerando que no era el encontrador un literato de profesión; y temiendo que el regionalismo o el Sr. Cotarelo tuviesen parte en aquella ocultación, ya estaba resuelta a publicar ejecutivamente la noticia del hallazgo -que, al fin, más derecho creo que tiene a un documento quien lo columbra mediante el estudio, que quien fortuitamente lo encuentra- cuando supe que el Sr. Palomares ofrecía a Vd. su descubrimiento para que fuese publicado en Revista de Archivos. Ante el nombre de Vd. me incliné con reverencia, contentísima de que se ofreciese el hallazgo a quien es por derecho propio, dueño y señor de toda noticia y de toda erudición española. El documento viniendo de sus manos de $\mathrm{Vd}$. a las mías viene consagrado; pero... lo que yo sentiría es que antes de llegar a mi libro lo recogiese en el suyo quien menos quisiera yo (si como creo su $2 .^{\circ}$ tomo sale antes que mi obra). El favor que me atrevo a rogar a $\mathrm{Vd}$. consiste pues en que si es posible, tenga la bondad de retrasar un poco la publicación del mss. de Tirso, a fin de que el primer libro que recoja la noticia y la incorpore a la biografía de Tirso, sea el mío; que, si Dios me da

y Cotarelo permanecía muy viva. 
vida, estaré muy pronto a las órdenes de Vd., y... a merced de la Academia donde me parece que no tengo ahora muchos amigos, aunque me honro en tener uno que vale por muchas academias. De eso y de cuanto a la publicación de mi libro se refiere deseo hablar a Vd. Perdone la desmedida extensión de esta carta, salude -le ruego- a su hermano D. Enrique y con respetuoso saludo de Vicente reciba la expresión de la bien sentida amistad de su más fervorosa y entusiasta admiradora ${ }^{23}$.

Lo que hace en esta carta Blanca de los Ríos es darle cuenta a Menéndez Pelayo de la existencia de la obra de Tirso titulada Vida de la santa madre doña María de Cervellón, cuyos milagros a favor de sus devotas le adquirieron el renombre de María del Socorro, de cuya redacción se tenía noticia por el propio fray Gabriel Téllez en su Historia de la Orden de la Merced. Una parte de este manuscrito autógrafo e inédito fue descubierto en el Archivo de la Delegación de Hacienda de Barcelona por Carlos Palomares, archivero de dicha delegación. El caso es que la erudita sevillana, a quien no se le ha dejado en Barcelona consultar el documento, sospecha que detrás de esa prohibición puede estar la larga mano de Cotarelo. Y ante el hecho de que el descubridor le ha comunicado que le ofrecía a Menéndez Pelayo copia del fragmento encontrado para que se publicara en la Revista de Archivos, Bibliotecas y Museos, Blanca de los Ríos le ruega a su maestro que retrase la publicación del documento con el fin de que sea ella la que dé noticia del descubrimiento en el libro que está preparando sobre Tirso de Molina, ganando así por la mano a Cotarelo que está a punto de dar a las prensas su segundo tomo de las comedias de Tirso en la Nueva Biblioteca de Autores Españoles (NBAE), tomo que va a llevar una amplia introducción en la que se examina la vida y obras del mercedario.

Ocurre que, probablemente, doña Blanca, en el tiempo que va de la redacción de esta carta a la siguiente -entre las que hay solamente un mes de diferencia, la carta está datada el 26 de agosto de 1907- ha debido de ir reconcomiéndose, dándole vueltas a sus miedos y temores, a su celopatía en todo lo relacionado con Tirso, imaginándose extrañas y peligrosas maniobras de Cotarelo, creciendo su odio y antipatía hacia su enemigo, hacia el erudito que le disputaba el puesto de primera autoridad tirsiana. Y es que el contenido y el tenor de la siguiente carta a don Marcelino así lo muestran. Es más, en ninguna de las cartas que se conservan de doña Blanca a Menéndez Pelayo se destila tanta hiel como en esta. Permítaseme que la copie entera, a pesar de su extensión, porque no tiene desperdicio al ser este documento un ejemplo precioso, en primer lugar, del punto al que llegó la escritora andaluza en su enfrentamiento con Emilio Cotarelo; en segundo, por ofrecernos interesantes datos, siempre desde la perspectiva de Blanca de los Ríos, acerca de la relación entre Menéndez Pelayo y Cotarelo y, por último, por mostrarnos el papel de confidente de la tirsista que don Marcelino representó en esta polémica:

Insigne amigo y maestro: No contesté antes a su para mí tan honrosa y amable carta del 2 de este mes, deseando dar a Vd. más completa noticia de todo lo relativo al hallazgo de la Vida de Sta. María de Socós escrita por Tirso. A este fin, volví a escribir

23. Op. cit., volumen 19, carta 236. 
al mercenario P. Gazulla, pidiéndole me enterase muy al pormenor de cuanto supiera en el asunto, y, entre tanto, desenterré de mi archivo tirsesco-mercenario cuantos datos poseo relativos a la Santa de Cervellón -que no son pocos-: $1^{\circ}$. - La oferta que Tirso hace en su Historia de la Merced de publicar en epítome, la Vida de la Santa, por extenso relatada en su Crónica. $2^{\circ}$. -Una mención a este epítome de Téllez contenida en una obra del P. Rivera, publicada en $1733.3^{\circ}$. - Un interesante relato de lo que Tirso llama "visura" del cuerpo de la Santa exhumado, para comprobar su incorruptibilidad, al comenzar el proceso de beatificación (Historia de la Merced). $4^{\circ}$.-Numerosas referencias de Tirso a Cataluña, que apoyan y amplían cuanto dije en el Ateneo de Barcelona. Recibí extensa carta del P. Gazulla en que volvía a contarme lo que dije a Vd. del hallazgo de la obrita de Tirso y me hablaba de la cita que de ella se hace en el indicado libro del P. Rivera, lo cual me probó que dicho mercenario -que estudia ahora el período primitivo de la Historia de su Orden; y es, como debe, grande admirador de Vd.-, tiene más noticias del opúsculo encontrado que su encontrador. Este P. Gazulla -que ha sido muy amable para mí ofreciéndome su incondicional auxilio para cuanto quiera yo investigar de su Orden- me dice también que la obrita de Tirso no caerá en las manos de Cotarelo, porque vendrá a la Revista de Archivos directamente. -Esto dijo también a Vicente el Sr. Hinojosa enterado de este asunto. -Pero... ¿y si en ausencia de Vd., Cotarelo, como Vd. teme, echando por delante su nombre, como Director de la Revista de Archivos, se apodera también de ese documento, y se me anticipa a publicar la noticia estropeándola, como tiene por costumbre? ¿Qué puede esperarse de quien como Vd. me dice- solicitó de Pidal en pago de su voto la plaza de Vd. de Director de la Biblioteca Nacional? Me lo habían dicho, y... tuve la cándida nobleza de dudarlo. ¡Era tan ruin la acción! Ella da la medida de la alteza moral y afectiva de ese hombre, que no es más alto intelectualmente. No es sino un madrugador literario; un anticipador de noticias que otros descubren; pero como va tanto de lo hallado por azar, a lo buscado con amor y esfuerzo consciente, el uso que él hace de tan mal adquiridas riquezas delata su condición intelectual. Se viste con las noticias que otros descubrieron, como se vestiría un salteador con las ropas de un duque, sin saber cuáles prendas son para los pies, ni cuáles para la cabeza, y él mismo delata su hurto. Para vestirse de duque, hay que nacer duque; y para escribir de arte, hay que nacer artista. Crea Vd. que me enciende la sangre («me quemo vivo» que diría Goya) cuando veo a ese jayán manosear las riquezas artísticas de Tirso con tanta torpeza y desaseo... Se necesita ser... Cotarelo para hablar con tan estupefaciente aplomo de todo lo que no sabe. Ver que Tirso era juntamente un gran mercenario teólogo y un gran dramático y ponerse a biografiarle y a juzgarle sin saber palabra de la Merced, ni.... de lo otro, es... jser Cotarelo! Adjuntos algunos botones de muestra de la botonadura que usa ese caballero. Y... perdóneme Vd. el desahogo; pero siendo Vd. el más ofendido, comprenderá toda la razón con que me quejo de un hombre que siendo la misma ignorancia quiso arrebatar a $\mathrm{Vd}$. la Dirección de la Biblioteca. No extrańará Vd., pues, que yo tema que me arrebate hasta la respiración; y que ante el temor de que siga madrugando, para hacerme, con tales méritos, la más injusta guerra en la Academia ${ }^{24}$, me haya yo resuelto a escribir

24. Parece que la escritora se refiere aquí a sus aspiraciones a entrar en la RAE echándole la culpa a Cotarelo de ponerle todo tipo de trabas. El caso es que la candidatura de Blanca de los Ríos a la Real Academia Española fue avalada en 1928 por Serafín Álvarez Quintero, el conde las Navas y el doctor Carlos María Cortezo, es decir, varios años después de 1907 y muerto ya Menéndez Pelayo. Los otros dos candidatos eran Agustín González de Amezúa, que fue el elegido, y Ramón Pérez de Ayala. Blanca de los Ríos obtuvo cinco votos, lo que la colocó en tercer lugar, impidiéndole entrar en la segunda votación. A este respecto, señala juiciosamente Alonso Zamora Vicente (op. cit., p. 494) lo que sigue: «En torno a la señora De los Ríos, se levantó una polvareda informativa que no suele ser del gusto de la Academia, por la facilidad con que suele caer en ángulos que no son de los más limpios criterios. Además, presidía ya Menéndez 
para «El Imparcial», un artículo, donde repitiendo el Procedimiento empleado en el anterior (1 $1^{\circ}$ de Octubre de 1906) eche mis ochavitos literarios a la alcancía de la publicidad, antes que me los apañe ese aprovechado afanador de cuanto Dios creó. Mi artículo se titulará "Tirso y Cataluña» y en él intentaré cumplir la oferta hecha al Ateneo Barcelonés de ampliar las noticias que allí adelanté sobre las relaciones de Tirso con el Principado. Consignaré la promesa que hace Tirso en su Crónica, de publicar en epítome, la Vida de Sta. Ma de Socós; la mención que a este epítome se contiene en el libro del P. Rivera, y la noticia (solo la noticia) del hallazgo de ese opúsculo, sin describirlo, para no desflorar el descubrimiento; por si, en efecto, llegase a manos de Vd. Con este anuncio no creo que le quito, sino antes le doy publicidad e interés al hallazgo. De todos modos, nada he querido hacer, sin enterar a Vd. plenamente y esperar sus ordenes. Conté -en confianza- el caso a nuestro buen amigo (que lo es mío de toda la vida) Rodríguez Marín y aprobó mi proyecto; pero le dije que yo escribiría a Vd. ante todo. No nos cansábamos de asombrarnos de la audacia e ingratitud cotarelescas, para con quien solo agradecimiento y reverente admiración debía merecerle... Pero él es así de exquisito, y a su semejanza, sus obras. No acierto a encarecer a $\mathrm{Vd}$. bastante mi gratitud por su bondadosa oferta de apoyarme en la Academia, aun temiendo que "seremos derrotados". Teniéndole a Vd. de mi parte, mi derrota será triunfo, y más si considero que para el grueso de los inmortales mi mayor delito parece ser ahora el haberme honrado contribuyendo al Homenaje de quien vale más que todas las Academias. ¡No uno, mil premios académicos daría yo por merecer el apoyo y aprobación del maestro de maestros! Trabajaré cuanto pueda y cuando Vd. venga le pediré su sabio consejo. De Vd. siempre respetuosa amiga y admiradora ${ }^{25}$.

La carta que se acaba de citar puede dividirse en dos partes con sus consiguientes comentos. En la primera, la escritora sevillana vuelve a contarle a su corresponsal, aunque aporta nuevos datos, el asunto del hallazgo de parte del manuscrito de la obra de Gabriel Téllez Vida de Santa María de Socós y reitera su preocupación acerca de la posibilidad de que Cotarelo, cuando llegue la copia del documento a la Revista de Archivos, Bibliotecas y Museos -que es en donde va a aparecer el artículo en el que Menéndez Pelayo dará cuenta del texto tirsiano- ${ }^{26}$, se haga con él y se anticipe a publicar la noticia «estropeándola, como tiene por costumbre».

Nótese cómo esto le da pie a Blanca de los Ríos para ensartar puntada tras puntada contra Emilio Cotarelo. La primera, verdaderamente, viene del propio Menéndez Pelayo quien le había contado a su fiel discípula que Cotarelo le había pedido a Alejandro Pidal, en pago de su voto en la elección a director de la Real Academia Española, el cargo de Director de la Biblioteca Nacional, cargo que ocupaba don Marcelino. Se ha visto la reacción de la remitente:

Pidal, y era secretario Emilio Cotarelo, personas que sabían muy bien, cada cual a su manera, en qué consistía la investigación histórico-literaria. Los dos, además, tenían conocimientos tirsistas de primerísima mano. No quiere decir esto que ahí estuviera el quid del rechazo, sino, simplemente, que la Academia vio en González de Amezúa y su tarea algo mucho más estimable y acorde con sus planes y necesidades».

25. Ibid., volumen 19, carta 263.

26. Véase Marcelino Menéndez Pelayo, «Una obra inédita de Tirso de Molina», Revista de Archivos, Bibliotecas y Museos, 18, 1908, p. 1-17. 
Ella [la acción de pedir el cargo] da la medida de la alteza moral y afectiva de ese hombre, que no es más alto intelectualmente. [...] Y... perdóneme Vd. el desahogo; pero siendo $\mathrm{Vd}$. el más ofendido, comprenderá toda la razón con que me quejo de un hombre que siendo la misma ignorancia quiso arrebatar a Vd. la Dirección de la Biblioteca.

\section{Con todo, lo más interesante es la descripción del laboreo intelectual de Cotarelo hecho por doña Blanca:}

No es sino un madrugador literario; un anticipador de noticias que otros descubren. [...] Se viste con las noticias que otros descubrieron, como se vestiría un salteador con las ropas de un duque, sin saber cuáles prendas son para los pies, ni cuáles para la cabeza, y él mismo delata su hurto. Para vestirse de duque, hay que nacer duque; y para escribir de arte, hay que nacer artista. Crea Vd. que me enciende la sangre («me quemo vivo» que diría Goya) cuando veo a ese jayán manosear las riquezas artísticas de Tirso con tanta torpeza y desaseo... Se necesita ser... Cotarelo para hablar con tan estupefaciente aplomo de todo lo que no sabe. Ver que Tirso era juntamente un gran mercenario teólogo y un gran dramático y ponerse a biografiarle y a juzgarle sin saber palabra de la Merced, ni.... de lo otro, es... jser Cotarelo!

No deja de ser interesante, a propósito de las últimas palabras de dońa Blanca, que las tachas que le pone a la tarea erudita de Cotarelo en la carta de 26 de agosto de 1907 son exactamente las mismas, aunque evidentemente en un tono distinto al de una carta misiva, que aparecen cuando da a las prensas su conocida conferencia leída en el Ateneo de Madrid el 23 de abril de 1906 y titulada "Tirso de Molina» ${ }^{27}$. Es, precisamente, en el apartado de las notas a pie de página de la versión de 1910 donde la autora enmienda a Cotarelo en un buen número de ocasiones. No puede olvidarse que el erudito asturiano había publicado en 1893 su libro Tirso de Molina. Investigaciones bio-bibliográficas $^{28}$, así como los dos tomos de las comedias de Tirso en la NBAE29. El objetivo último de la tirsista andaluza es demostrar, y se entrega con verdadera fruición a ello, que Cotarelo no ha consultado los documentos originales que se custodian en diferentes archivos espańoles y que se ha limitado a sacarle rendimiento a lo que otros estudios de la vida y obra de Tirso han investigado y publicado:

por no haber su autor [Emilio Cotarelo] consultado las fuentes originales, no añadió noticia alguna capital a la biografía de Tirso, ni rectificó los errores cometidos por los anteriores biógrafos. En su última obra acerca de Téllez (Comedias de Tirso de Molina; Nueva Biblioteca de Autores Españoles) tampoco aporta el Sr. Cotarelo datos nuevos de propia investigación: recoge los allegados por D. Bartolomé J. Gallardo, Manuel Serrano Sanz y D. Cristóbal Pérez Pastor, renunciando a los trabajos de indagación personal, sin duda por creerlos inútiles ${ }^{30}$.

27. La conferencia se publicó ese mismo año en Madrid por la Imprenta de Bernardo Rodríguez. Cuatro años después la recoge Blanca de los Ríos en su libro Del Siglo de Oro (Estudios literarios), Madrid, Imprenta de Bernardo Rodíguez, 1910, p. 1-55. Citaré por esta edición de la conferencia.

28. Emilio Cotarelo, Tirso de Molina. Investigaciones biobibliográficas, Madrid, Imprenta de Emrique Rubiños, 1893.

29. Emilio Cotarelo, Comedias de Tirso de Molina, Madrid, Bailly-Baillière e Hijos, 19061907.

30. Op. cit., p. 12, nota 1. 
De manera que le está acusando, de un modo más educado ciertamente, de lo mismo que ya hemos visto en la carta de 1907, es decir, de servirse de los hallazgos que otros con mucho esfuerzo han logrado descubrir. Lo que es lo mismo que negarle cualquier autoridad científica y literaria en lo tocante a la vida y obra de Tirso de Molina.

Téngase muy presente que estas palabras de la Sra. De los Ríos aparecen, en su versión definitiva - conforme ha quedado dicho- en el libro titulado Del Siglo de Oro, publicado en 1910, y que lleva un prólogo de 44 páginas firmado por Menéndez Pelayo. Dicho de otra manera: don Marcelino avala con su prólogo las andanadas críticas que su fiel Blanca de los Ríos le lanza a Emilio Cotarelo.

El propio Cotarelo respondió ese mismo 1906 a la tirsista sevillana en su artículo-reseña "Examen de una conferencia acerca de Tirso». La sustancia de su reseña está en que el autor le acusa a la Sra. de los Ríos de, precisamente, no aportar nada nuevo ni original a lo que ya se sabe de Tirso: «todos los demás hechos [excepción de un dato relativo a la licencia de embarque para la Española de Tirso dada por la casa de contratación de Sevilla] son ya hace algunos ańos del dominio público» ${ }^{31}$.

Más adelante pone de relieve las equivocaciones en las que incurre la tirsista $\mathrm{y}$, asimismo, se dedica a mostrar una por una las aportaciones de su libro de 1893. Con no poca astucia, Cotarelo incluye en su reseña unas palabras de Menéndez Pelayo sacadas de un artículo que el erudito cántabro publicó en 1893 en la España Moderna respecto al libro del propio Cotarelo:

Es tanto lo que la diligencia del Sr. Cotarelo ha desentrañado, que, sin necesidad de amplificaciones, ni de fárrago, ha logrado convertir en 78 páginas los 78 renglones próximamente que constituían la más copiosa de las biografías de Tirso conocidas hasta ahora. [...] De hoy más no será lícito escribir la vida de Tirso con la incuria y el desmaño con que hasta ahora venía haciéndose ${ }^{32}$.

El caso es, pues, que entre 1906 y 1910 dos de las autoridades literarias más importantes del momento por lo que se refiere al teatro del Tirso de Molina: Emilio Cotarelo y Blanca de los Ríos, polemizan en torno a la vida y obra del dramaturgo mercedario. A mi modo de ver, lo destacable de esa controversia no son solo los argumentos que cada uno de los polemistas esgrimieron, sino también la circunstancia, que he tratado de mostrar, de que en la trastienda de ese combate intelectual tuvo mucha importancia la actitud de cada uno de ellos con respecto a Menéndez Pelayo. Ello constituye un botón de muestra más del peso de la autoridad científica y literaria que don Marcelino tuvo, ha tenido y tiene en la historia y crítica de la literatura española.

31. Emilio Cotarelo, "Examen de una conferencia acerca de Tirso de Molina», Madrid, Imprenta de la Revista de Archivos, 1906. La cita en la p. 5.

32. Op. cit., p. 11. La reseña de Cotarelo termina con estas palabras: «Esperamos confiadamente en que [...] sabrá la Sra. de los Ríos darnos en su futuro y tan largo tiempo esperado libro una crítica amplia, exacta y generosa, que, en vez de entorpecer, pueda ilustrar el estudio de nuestro grandioso teatro nacional» (op. cit., p. 20). 
